\title{
The effect of carbon impurities on molybdenum surface morphology evolution under high-flux low-energy helium ion irradiation
}

\author{
J. K. Tripathi* , T. J. Novakowski, S. Gonderman, N. Bhardwaj, and A. Hassanein \\ Center for Materials Under Extreme Environment (CMUXE), School of Nuclear Engineering \\ Purdue University, West Lafayette, IN-47907, USA
}

\begin{abstract}
We report on the role of carbon (C) impurities, in molybdenum (Mo) fuzz evolutions on Mo surface during $100 \mathrm{eV} \mathrm{He}^{+}$ion irradiations. In this study we considered $0.01,0.05$, and $0.5 \% \mathrm{C}^{+}$ ion impurities in $\mathrm{He}^{+}$ion irradiations. For introducing such tiny $\mathrm{C}^{+}$ion impurities, gas mixtures of $\mathrm{He}$ and $\mathrm{CH}_{4}$ have been chosen in following ratio; 99.95: 0.05, 99.75: 0.25, and 97.5: 2.5. Apart from these three cases two additional cases, $100 \% \mathrm{He}^{+}$ion (for Mo fuzz growth due to only $\mathrm{He}^{+}$ions) and $100 \% \mathrm{H}^{+}$ion (for confirming the significance of tiny $0.04-2.0 \% \mathrm{H}^{+}$ions in terms of Mo fuzz evolutions on Mo surface, if any), have also been considered. Ion energy (100 $\mathrm{eV})$, ion fluence $\left(2.6 \times 10^{24}\right.$ ions $\left.\mathrm{m}^{-2}\right)$, and target temperature $(923 \mathrm{~K})$ were kept constant for each experiment and their selections were based on our previous studies [1, 2]. Our study shows homogeneously populated and highly dense Mo fuzz evolutions on entire Mo surface for 100\% $\mathrm{He}^{+}$ion irradiation case. Enhancement of $\mathrm{C}^{+}$ion impurities in $\mathrm{He}^{+}$ions causes a sequential reduction in Mo fuzz evolutions, leading to almost complete prevention of Mo fuzz evolutions for $0.5 \% \mathrm{C}^{+}$ion impurity concentrations. Additionally, no fuzz formation for $100 \% \mathrm{H}^{+}$ion irradiation at all, were seen (apart from some tiny nano-structuring, in very limited regions). This indicates that there is no significant role of $\mathrm{H}^{+}$ions in Mo fuzz evolutions (at least for such tiny amount, $0.04-2.0 \% \mathrm{H}^{+}$ions). The study is significant to understand the behavior of potential
\end{abstract}

\footnotetext{
${ }^{*}$ corresponding author email: jtripat@purdue.edu
} 
high-Z plasma facing components (PFC), in presence of tiny amount of $\mathrm{C}$ impurities, for nuclear fusion relevant applications.

Keywords: Plasma-facing materials, molybdenum, fuzz formation, ion irradiation, atomic force microscopy, X-ray photoelectron spectroscopy, optical reflectivity

PACS: $\quad$ 61.80.Jh, 68.37.Ps, 82.80.Pv, 68.37.Hk

\section{Introduction:}

There are very stringent requirements regarding the properties of plasma-facing components (PFCs) materials in fusion devices for the divertor and first wall in the International Thermonuclear Experimental Reactor (ITER) [3] . Until recently it was envisaged that the ITER divertor would include two tiers; the armor for lower and upper parts consisting of carbon fiber composites (CFC) and tungsten (W), respectively $[\underline{4}, \underline{5}]$. ITER and future fusion devices will use the hydrogen $(\mathrm{H})$ isotopes, i.e., deuterium (D) and tritium $(\mathrm{T})$ to fuel the fusion reaction. The fusion of $\mathrm{H}$ isotopes atoms produces a heavier element, helium $(\mathrm{He})$ [6]. The presence of impurities such as $\mathrm{O}$ and $\mathrm{C}$ in the plasma can significantly affect the rates at which PFCs will be eroded [7]. Although, currently there is no plans to use carbon or CFC as PFCs in ITER; still the existence of $\mathrm{C}$ contamination in any fusion device's plasma chamber (in particular, in futures demonstration (DEMO) fusion power plants) is always possible. Currently tungsten (W) is the leading candidate material for the divertor. $\mathrm{W}$ is a refractory metal and has very high melting temperature (3695 K). However, W has few challenges as compared to C, specifically during extremely high heat loads in presence of plasma (which ITER will require, under future fusion performance). The two major challenges are possible melting of $\mathrm{W}$ during very high heat flux (nuclear fusion environment in ITER) and its tolerance only in minute concentrations in the 
burning plasma core (since it can cause strong energy losses from the core, if high- $Z$ ions accumulate in the center). $\mathrm{C}$, on the other hand, does not melt but sublimes and is low-Z, so can be tolerated in larger quantities than $\mathrm{W}$ in the core plasma. Incidentally, $\mathrm{C}$ is a difficult choice for ITER nuclear phase operations as a result of its great capacity for retaining invaluable $\mathrm{T}$ fuel and efficiently trapping it inside the vacuum vessel. W retains fusion fuel only at comparatively low levels than C.

The selection of $\mathrm{W}$ in ITER was based on its higher melting point (3695 K), lower sputtering yield, and strong mechanical properties [8-12]. However, the continued investigations on $\mathrm{W}$ have shown that it undergoes severe morphology changes, during low energy He plasma and/or ion irradiation under fusion-like extreme conditions $[\underline{13}, \underline{14}]$. In addition to the morphology change, the retention properties of tungsten $\mathrm{W}$ are also subject to change when exposed to $\mathrm{He}$ and/or $\mathrm{D}$ ion irradiations. The physical mechanisms responsible for such deterioration are not very clear yet, although several modeling and simulations viz., molecular dynamic, multiscale and atomistic approaches have been attempted [15-22]. Therefore, studying similar structure evolutions on other refractory metal surfaces, such as Mo (as in the present case), is worthwhile which exhibit similar interesting properties for thermonuclear fusion environments such as resistance to heat, wear, and sputtering [23]. In addition, Mo is also considered for diagnostics tools, such as invessel mirrors which are in the first wall of ITER [23]. Note that, the single crystal mirrors made of these high-Z materials exhibited quite better ability to withstand erosion conditions and had sufficient lifetime [24]. Thus we continued to study ways to improve and advance the nuclear materials performance for future nuclear energy systems using low-energy high-flux $\mathrm{He}^{+}$ion irradiations. In this study, we demonstrated unique changes in Mo surface morphology, stoichiometry, and its optical properties as a function of target temperature; due to tiny $\mathrm{C}^{+}$ion 
impurities during $100 \mathrm{eV} \mathrm{He}^{+}$ion irradiations. The selection of substrate temperature (923K), ion energy $(100 \mathrm{eV})$, and ion fluence $\left(2.6 \times 10^{24}\right.$ ions $\left.\mathrm{m}^{-2}\right)$ were based on our previous studies [1 , 2]. In those studies, we showed clear temperature window of 823-1073K for Mo fuzz formation [1]. The observed temperature window is significantly lower and narrower than that for $\mathrm{W}$ case $(1000-2000 K)[14]$. The surface morphology of PFC materials play a vital role towards reliable steady state operation of any fusion reactor. Fuzz (fragile structure) growth on PFC materials takes place mainly at high temperatures (relative to melting point) during plasma material interaction. During the occurrence of such phenomena, highly dense nanostructured surface layers consisting of conglomerated nanorods develops on the PFC materials. This involves nanometer scale bubbles and/or tangled mass of disordered nanorods. The significant enhanced surface area, and fragility of such nanostructured surfaces, raise several serious concerns for the usefulness of such PFC materials (i.e., W and/or Mo) in fusion reactors. Fuzz can be eroded easily and so their growth in PFC materials is a major concern that may cause serious erosion of PFCs surface and plasma contamination and therefore, shorten its lifetime. Plasma contamination of high- $Z$ elements is a serious threat for the durability of the confined plasma. Thus the presence of such nanostructured materials, during abnormal events, even in very tiny amount, in the confined D-T plasma may lead to immediate plasma quenching due to radiation energy losses $[25, \underline{26}]$. This scenario is very much expected if the extremely fragile PFC material fuzz structure washed or splashed out into the confined plasma during transient events resulting from various plasma instabilities [25, 26].

Following our recent studies $[\underline{1}, \underline{2}, \underline{27}]$, in this report we focus on the role of $\mathrm{C}$ impurities on Mo PFC morphology evolution (Mo fuzz) under $100 \mathrm{eV} \mathrm{He}{ }^{+}$ion irradiation having a constant ion- 
fluence of $2.6 \times 10^{24}$ ions $\mathrm{m}^{-2}$ (ion-flux $7.2 \times 10^{20}$ ions $^{-2} \mathrm{~s}^{-1}$ ) at $923 \mathrm{~K}$ (Mo sample temperature; hereafter target temperature). Recent studies have shown that $\mathrm{C}$ contaminants on $\mathrm{W}$ surface may significantly reduce the W Fuzz formation [28-30]. Fuzz layer growth rate does not strongly depend on whether the $\mathrm{He}$ is the dominant, or a minority, species [28]. In fact, Fuzz can be inhibited if sufficient minute impurities (in the case of ITER, beryllium (Be) or C) are contained within the incident particle flux to achieve a condition of net deposition and thereby allow an impurity surface layer to develop [28]. However, if the removal rate of impurities from the surface is greater than their arrival rate to the surface, then the fuzz layer may still develop [28]. Although few studies have been reported perversely on the similar topic [31-33], all of them are on W PFC. To the best of our knowledge, the effects of intermixing of Mo PFC materials are still not reported and need to be investigated for deeper understanding of the underlying mechanisms involved during Mo fuzz formation process. Our study shows the responses of the Mo surface during $100 \mathrm{eV} \mathrm{He}^{+}$ion irradiation as a function of $\mathrm{C}^{+}$ion impurity concentrations (in the range of 0.01- $0.5 \%$ ). A recent report on ITER indicates that the temperature and ion energy spectra in the ITER divertor are currently believed to fall outside the W fuzz formation window (1000 2000K) [14] in the expected detached plasma regime. Nevertheless, fuzz formation window in future DEMO machines could still be significant as well as unexpected abnormal ITER operations. In these fusion devices, small amounts of $\mathrm{C}$ seeding might be considered, not just for the benefits of radiative cooling, but also to inhibit fuzz formation. Additionally small amounts of $\mathrm{C}$ in the DEMO may not cause a retention problem due to the extremely high operational temperature. 


\section{Experimental Conditions}

Experiments have been performed at the Center for Materials under Extreme Environment (CMUXE) at Purdue University in the surface characterization laboratories UHFI (Ultra-High Flux Irradiation) and IMPACT (Interaction of Materials with Particles and Components Testing) [2, 34]. Cold rolled Mo sheets of $99.95 \%$ purity and $0.5 \mathrm{~mm}$ thickness were used for these experiments; $10 \times 10 \mathrm{~mm}$ samples were cut from same Mo sheet and then mechanically polished to a mirror-finish surface. For He ion irradiation experiments, a Kaufman \& Robinson, Inc., End Hall (EH) 400 ion-source gun was used. Base pressure of the ultra-high vacuum (UHV) chamber was $5.0 \times 10^{-8}$ torr, although the pressure during ion irradiation was $1.0 \times 10^{-4}$ Torr. The selected ion energy $(100 \mathrm{eV})$, ion-flux $\left(7.2 \times 10^{20}\right.$ ions $\left.\mathrm{m}^{-2} \mathrm{~s}^{-1}\right)$, ion-fluence $\left(2.6 \times 10^{24}\right.$ ions $\left.\mathrm{m}^{-2}\right)$, and target temperature $(923 \mathrm{~K})$ were based on our previous studies $[\underline{1}, \underline{2}]$. For precise temperature measurement, we used thermocouples rather than radiation thermometers. A thermal-feedback mechanism is used in the sample heater and corrected for ion-induced heating of the Mo samples during the experiment. This is achieved by altering the current supplied to the heating element based on the difference between current and desired sample temperatures. In the present investigations, five different cases of ion beam compositions were considered, viz., $100 \%$ $\mathrm{He}^{+}$ion (hereafter pure $\mathrm{He}^{+}$ion); $99.95 \% \mathrm{He}^{+}$ion mixed with $0.01 \% \mathrm{C}^{+}$, and $0.04 \% \mathrm{H}^{+}$ions (hereafter $0.01 \% \mathrm{C}^{+}$ion); $99.75 \% \mathrm{He}^{+}$mixed with $0.05 \% \mathrm{C}^{+}$ion and $0.2 \% \mathrm{H}^{+}$ions (hereafter $0.05 \% \mathrm{C}^{+}$ion); $97.5 \% \mathrm{He}^{+}$mixed with $0.5 \% \mathrm{C}^{+}$and $2 \%$ of $\mathrm{H}^{+}$ions (hereafter $0.5 \% \mathrm{C}^{+}$ion); and $100 \% \mathrm{H}^{+}$ions (hereafter pure $\mathrm{H}^{+}$ion). The ion fluence $\left(2.6 \times 10^{24}\right.$ ions $\left.\mathrm{m}^{-2}\right)$ and target temperature (923K) were constant for each case. The variation of the ion beam composition was achieved by varying the concentration of the gas mixture $\left(\mathrm{He}\right.$ and $\left.\mathrm{CH}_{4}\right)$ fed into the ion source gun. Pure $\mathrm{H}^{+}$ion irradiation experiments were performed just for reference and/or comparison 
purpose, simply because in our experiments we used gas mixture and the mixture was He and $\mathrm{CH}_{4}$. After ion irradiation experiments, the samples were taken out from the UHV chamber. Then field emission (FE) scanning electron microscopy (SEM) was performed using a "Hitachi S-4800 Field Emission SEM" to monitor the $\mathrm{He}^{+}$ion-induced surface modifications. Atomic force microscopy (AFM) studies using Bruker Innova atomic force microscope, for monitoring the ion-induced nanoscopic changes, were also conducted on selected samples. XPS was used on pristine and all post-irradiated Mo targets. During the XPS measurements, the photoelectrons were excited by an X-ray source of $\mathrm{Mg}-\mathrm{K} \alpha($ energy $=1253.6 \mathrm{eV})$ radiation source (SPECS XRC1000). The emitted photoelectrons were analyzed with Omicron Argus hemispherical electron analyzer using a round aperture of $0.63 \mathrm{~mm}$ (for imaging-XPS) and a second aperture at $6.3 \mathrm{~mm}$ (for XPS). No sample charging was observed. All XPS spectra were analyzed with commercial Casa-XPS software [35]. Optical reflectivity measurements were performed over spectra of incident light (using a combination of halogen and deuterium light source and a beam diameter of $\sim 1 \mathrm{~mm}$ ) ranging from 200 to $1100 \mathrm{~nm}$ wavelengths. Before the reflectivity measurements began, the spectrometer was calibrated with a Spectralon white reference plate having $100 \%$ reflectivity. Note, the observed reflection in our optical reflectivity system is mainly specular. A specular reflection is a reflection of a mirror-like surface (keeping in mind that different surfaces to different wavelengths may or may not be mirror-like). Specular reflection will result when the surface roughness is smaller than the applied wavelength of light (and diffuse reflection will result when the surface roughness is larger than the wavelength). A specular reflectance of $100 \%$ would correspond to an ideal mirror, typical specular reflectance is less than the maximum value (i.e., 100\%). For collecting the reflected light, a "reflection probe" from Ocean Optics has been used which can collect light at the same angle as it illuminates, and can be used for either 
specular or diffuse reflection measurements. The "reflection-probe" is made of 6 illumination fibers around a single read fiber (in the center), which results in a $25^{\circ}$ full angle field of view. Each illumination fiber project a cone of light from the source and all of them overlap at the sample in the center, exactly where the central read fiber is situated. Thus, in principle the reflectivity for an ideal mirror will be $\sim 100 \%$. During our measurements the "reflection probe" was placed at $90^{\circ}$ to the sample surface (along the sample surface normal). The distance between sample and "reflection probe" was $\sim 1 \mathrm{~mm}$. Maya 2000 Pro Spectrometers from Ocean Optics was used for the signal detection.

\section{Results and Discussion}

\subsection{Scanning electron microscopy (SEM) and atomic force microscopy (AFM) studies}

Figure 1 depicts FE-SEM images of pristine and irradiated mechanically polished to a mirror finish Mo samples. Ion irradiation experiments were performed at 923K target temperature, for five different cases, viz., pure $\mathrm{He}^{+}$ion, $0.01 \% \mathrm{C}^{+}$ion, $0.05 \% \mathrm{C}^{+}$ion, $0.5 \% \mathrm{C}^{+}$ion, and pure $\mathrm{H}^{+}$ ion. Ion energy $\left(100 \mathrm{eV}\right.$ ) and ion-fluence $2.6 \times 10^{24}$ ions $\mathrm{m}^{-2}$ (ion flux of $7.2 \times 10^{20}$ ions $^{-2} \mathrm{~s}^{-1}$ ) was kept constant for each case. As evidenced in Fig. 1(a), SEM result shows a reasonably clean and flat surface morphology, up to several micrometer scales, along with a few mechanicalpolishing induced scratches (marked with blue arrows). However, for pure $\mathrm{He}^{+}$ion irradiation case, homogenously populated nano-tendril fiber form structures or fuzz were observed (Fig. 1(b)). The homogenously populated Mo fuzz were dense enough, and so the entire Mo sample was showing dark-black colored surface ( 0\% optical reflectivity for $670 \mathrm{~nm}$ wavelength; will be detailed in section 3.3). Similar Mo fuzz evolutions were recently observed in our [1, $\underline{2}]$ and others studied [타.. He is a chemically inert gas with almost zero solubility in almost all metals (Mo, in the present case). However, it can diffuse rapidly through the Mo surface because of its 
smaller size, leading to He bubble formation underneath the surface at crystallographic defects. He irradiation induced damages can be so significant that, they can damage the surface even in the absence of displacement damage and native defects [구 $\underline{38]}$. Recent studies suggest that, the process of He bubble formation is responsible for such Mo fuzz growth $[\underline{1}, \underline{2}, \underline{36}]$. The measured average Mo fuzz lengths and diameters of $\sim 94$ and $\sim 43 \mathrm{~nm}$, respectively. Protrusions of these Mo fuzz from the sample surface are noteworthy. After introducing $0.01 \% \mathrm{C}^{+}$ion impurOities in $\mathrm{He}^{+}$ ions, Mo fuzz protrusions were reduced significantly as evidence in Fig. 1(c). Similar trend was continued for $0.05 \% \mathrm{C}^{+}$ion case, where Mo fuzz protrusions are almost zero (Fig. 1(d)). For $0.5 \% \mathrm{C}^{+}$ion impurity case, only thick carbon layer was observed (Fig. 1(e)); showing no Mo fuzz at all on the Mo surface. The sequential changes in rms roughness values (calculated from AFM analysis; will be detailed, below $), 9.1 \mathrm{~nm}\left(0.01 \% \mathrm{C}^{+}\right.$ions $)$to $10.2 \mathrm{~nm}\left(0.05 \% \mathrm{C}^{+}\right.$ions $)$to $21.1 \mathrm{~nm}\left(0.5 \% \mathrm{C}^{+}\right.$ions $)$, are in well corroboration with these facts. The enhancement in rms roughness values are due to $\mathrm{C}$ adatoms nucleation (and reduction in Mo fuzz density). XPS investigations on these samples show the formation of $\mathrm{Mo}_{2} \mathrm{C}$ and pure $\mathrm{C}$ phase formations (will be detailed latter in section 3.2). Such huge reduction in Mo fuzz protrusions and $\mathrm{Mo}_{2} \mathrm{C}$ phase formation can be understood in the realm of ion induced intermixing as follows. The $100 \mathrm{eV}$ ion irradiation, in such extreme conditions (at high target temperature 923K and high ion-flux), enhances the surface atom relocation frequency about the thermal level and intensifies the surface restructuring processes. Adsorbed $\mathrm{C}$ atoms on the fuzzy Mo surface move to reduce the induced surface energy perturbations and to optimize the bonding. This often results in a massive reconstruction which may requires surface diffusion over distances of several atomic bonds [39]. The dynamic state of the surface supported by adsorption of reactive species, under ion irradiation at such elevated temperature, may create imperfect surface structure and modify the 
composition significantly [40]. Additionally, the surface restructuring can be significantly enhanced by increasing the adsorbed $\mathrm{C}$ atoms coverage [41]. Such restructured surface will be stabilized when surface will be covered by continuous layer of adsorbate. The excessive surface chemical potential as compared to that of the grain boundaries produces a net adatoms flow into the grain boundaries, leading to the generation of compressive stresses in the grains [40]. The adsorbed mobile $\mathrm{C}$ adatoms, interacting at the grain boundaries of fuzzy Mo surface, may be driven into the bulk Mo through the interface by the difference of chemical potentials between activated Mo surface and its grain boundaries [40]. At such high temperature (923K), the mobility of $\mathrm{C}$ adatoms at the Mo surface increases and transported into the bulk Mo as well, driven by chemical potential gradient. Finally, in the last case, $100 \mathrm{eV}$ pure $\mathrm{H}^{+}$ion irradiation experiment was also performed, and the surface modification results were shown in Fig. 1(f). Note, this experiment was performed for confirming whether the tiny percentage $(0.04-2 \%)$ of $\mathrm{H}^{+}$ions, in our previous irradiation experiments, will have any significance in terms of Mo fuzz structure tailoring. As evidenced in Fig. 1(f), there is no significant distinctive features, viz., Mo fuzz, surface pinholes and/or blistering. However, in very limited dispersed surface areas, a few notable nanostructures $\sim 25 \mathrm{~nm}$ in dimeters were observed. The formation of such distinctive structure is most likely crystal orientation dependent. Furthermore for gaining the quantitative information about the surface - roughness and -morphology, high-resolution AFM studies were also performed, on selected samples. Figure 2 depicts 3D AFM images (in topography mode) and corresponding line profiles (along the marked green lines on the corresponding images) for $0.01,0.05$, and $0.5 \% \mathrm{C}^{+}$ion impurity (in $\mathrm{He}^{+}$ions) irradiated Mo samples. Likewise, SEM studies, even for $0.01 \% \mathrm{C}^{+}$ion impurity irradiation, there is significant $\mathrm{C}$ grain coverage on Mo fuzzy surface (Fig. 2 (a)-(b)). The $\mathrm{C}$ grain coverage increases sequentially with increasing $\mathrm{C}^{+}$ion 
impurities leading to corresponding enhancement in the $\mathrm{C}$ grain size (on top surface) from $\sim 80$ $\mathrm{nm}\left(0.01 \% \mathrm{C}^{+}\right.$ion $)$to $\sim 100 \mathrm{~nm}\left(0.05 \% \mathrm{C}^{+}\right.$ion $)$to $\sim 140 \mathrm{~nm}\left(0.5 \% \mathrm{C}^{+}\right.$ion $)$in diameter. The formation of $\mathrm{C}$ grains can be understood in the realm of nucleation of $\mathrm{C}$ adatoms. When atomic $\mathrm{C}$ are created, from the dissociation of hydrocarbon precursors, on the substrate (Mo in present case) surface, a few $\mathrm{C}$ atoms may attach to each other and form a nucleus. $\mathrm{C}$ cluster made by the coalescence of theses nuclei keeps growing to form $\mathrm{C}$ domain through an adatom diffusion of $\mathrm{C}$ atoms. As time elapse these domains eventually meet and form a boundary [42]. After performing sectional analysis on AFM images, a sequential enhancement in rms roughness values with increasing $\mathrm{C}^{+}$ion impurities, have been observed, viz, $9.1 \mathrm{~nm}\left(0.01 \% \mathrm{C}^{+}\right.$ions $)$to $10.2 \mathrm{~nm}\left(0.05 \% \mathrm{C}^{+}\right.$ions $)$to $21.1 \mathrm{~nm}\left(0.5 \% \mathrm{C}^{+}\right.$ions $)$. The enhancement in $r m s$ roughness values can be understood in the realm of $\mathrm{C}$ adatoms nucleation (and reduction in Mo fuzz density). The observed AFM results corroborates well with SEM studies.

\subsection{X-ray Photoelectron Spectroscopy (XPS) Studies}

For investigating the Mo surface composition changes due to $100 \mathrm{eV}$ ion beam irradiationinduced surface modifications at various temperatures, ex-situ core level XPS were also conducted for all samples. Figure 3 shows the survey core level XPS spectra of pristine and $100 \mathrm{eV} \mathrm{He}^{+}$ion irradiated (at 923K) mirror-finished polished Mo samples, as a function of $\mathrm{C}^{+}$ ion impurity. Data for irradiated Mo samples are vertically shifted for clarity of the figure. Figure 3 also shows the survey in-situ core level XPS spectra of $1 \mathrm{keV} \mathrm{Ar}^{+}$ion-sputter-cleaned pristine Mo sample. This experiment was performed to determine chemical compositions of Mo samples without exposing them in to open air atmosphere. The in-situ core level XPS spectra of the sputter-cleaned pristine sample show only Mo XPS peaks. No impurity or C and O peaks (Fig. 3) were observed. However, the ex-situ core level XPS spectra on the pristine Mo sample show the 
presence of $\mathrm{MoO}_{3}-3 \mathrm{p}$ and $\mathrm{MoO}_{3}-3 \mathrm{~d}$ doublets, O-1s and C-1s peaks but no impurity. Similar trends have been seen for $100 \mathrm{eV} \mathrm{C}^{+}$ion mixed $\mathrm{He}^{+}$ion irradiated Mo samples too. Figure 3 also shows enhancement in the C-1s XPS peak area (and corresponding reduction in the O-1s XPS peak area) with increasing $\mathrm{C}^{+}$ion impurity $\%$ in original $\mathrm{He}^{+}$ions. Figure 4 describes the highresolution ex-situ core level XPS spectra for Mo-3d doublet (left column) and C-1s (right column) XPS peaks, for pristine (and $1 \mathrm{keV} \mathrm{Ar}^{+}$ion-sputter-cleaned pristine, for reference) and $\mathrm{C}^{+}$ion impure $\mathrm{He}^{+}$ion-irradiated Mo samples. All spectra were resolved into their respective components by a mixed Gaussian-Lorentzian (GL, $m=30$ ) line shape (where $m=0$ is pure Gaussian and $m=100$ is pure Lorentzian) using commercial Casa-XPS peak-fitting software [35]. For background subtraction we used Shirley background subtraction method. For all highresolution XPS spectra, the major fitting parameters, binding energy (BE) and full width at half maxima (FWHM) are summarized in Table-1. As expected, the in-situ core level XPS spectra for Mo-3d doublets of the sputter-cleaned pristine Mo sample shows the presence of Mo-3d $\mathrm{d}_{3 / 2}$ $(231.6 \mathrm{eV})$ and Mo-3d $\mathrm{d}_{5 / 2}(228.5 \mathrm{eV})$ XPS peaks [43-45] that confirm the metallic Mo in the samples; no impurity, including that of oxidized $\mathrm{Mo}\left(\mathrm{MoO}_{3}\right)$, was seen (left column, Fig. 4). However, ex-situ XPS for the pristine sample shows the presence of metallic Mo-3d doublet XPS peaks $\mathrm{Mo}_{3 / 2}(231.2 \mathrm{eV})$ and Mo- $3 \mathrm{~d}_{5 / 2}(228.6 \mathrm{eV})$ XPS peaks [43-45], in addition to oxidized Mo-3d doublet XPS peaks $\mathrm{MoO}_{3}-3 \mathrm{~d}_{3 / 2}(236.5 \mathrm{eV})$ and $\mathrm{MoO}_{3}-3 \mathrm{~d}_{5 / 2}(233.3 \mathrm{eV})$ XPS peaks (left column, Fig. 4) [43-45]. Because the pristine samples were open-air exposed, the thin $\mathrm{MoO}_{3}$ layer on the top surface was expected. However, $100 \% \mathrm{He}^{+}$ion irradiated Mo sample show, only $\mathrm{MoO}_{3}-3 \mathrm{~d}$ doublet peaks. The absence of Mo-3d doublets, for this case, can be understood in the realm of sufficiently thick open air oxidized Mo-fuzz, on top surface $[\underline{1}, \underline{2}]$. On the other hand, $0.05 \% \mathrm{C}^{+}$ion impurity $\mathrm{He}^{+}$ion irradiation causes the appearance of additional (in 
addition to $\mathrm{MoO}_{3}-3 \mathrm{~d}$ doublets, as of seen in $100 \% \mathrm{He}^{+}$ion irradiation case) molybdenum carbide $\mathrm{Mo}_{2} \mathrm{C}-3 \mathrm{~d}$ doublet XPS peaks: $\mathrm{Mo}_{2} \mathrm{C}-3 \mathrm{~d}_{3 / 2}(231.7 \mathrm{eV})$ and $\mathrm{Mo}_{2} \mathrm{C}-3 \mathrm{~d}_{5 / 2}(228.6 \mathrm{eV})$ XPS peaks (left column, Fig. 4) [46-48]. For enhancing the understanding of existing $\mathrm{C}$ compositions in $\mathrm{C}^{+}$ion impure $\mathrm{He}^{+}$ion irradiated Mo samples, high-resolution C-1s XPS spectra have also been recorded and analyzed, and the results are depicted in the right-column of Fig. 4. The major fitting parameters, BE and FWHM are summarized in Table 2. As evidenced in Table-2 and Fig. 4 (right-column), in addition to graphite (C-C) phase we observed $\mathrm{C}=\mathrm{O}, \mathrm{O}-\mathrm{C}=\mathrm{O}$, and molybdenum carbide $\left(\mathrm{Mo}_{2} \mathrm{C}\right)$ XPS peaks [46-48] for all $\mathrm{C}^{+}$ion impure $\mathrm{He}^{+}$ion irradiated Mo samples. $\mathrm{Mo}_{2} \mathrm{C}$ formation, in such extreme conditions, is expected (the same we observed in high-resolution XPS peak of Mo-3d case). In this regard the study by L.N. Aleksandrov et al. is siginificant where thay have reported that, when $\mathrm{C}$ concentration in Mo attains 0.15 mass $\%$, the molybdenum carbide $\mathrm{Mo}_{2} \mathrm{C}$ formation occurs [49]. Based on our high-resolution Mo-3d and C1s XPS results we made calculations for at.\% (atomic concentrations) of $\mathrm{Mo}, \mathrm{MoO}_{3}, \mathrm{Mo}_{2} \mathrm{C}, \mathrm{C}-\mathrm{C}$, $\mathrm{C}=\mathrm{O}$, and $\mathrm{O}-\mathrm{C}=\mathrm{O}$ and the results are summarized in Table- 3 . The table shows a sequential significant enhancement in the graphite carbon $(\mathrm{C}-\mathrm{C}), \mathrm{C}=\mathrm{O}$, and $\mathrm{O}-\mathrm{C}=\mathrm{O}$ (and corresponding reduction in the $\mathrm{Mo}_{2} \mathrm{C}$ ) with increasing $\mathrm{C}^{+}$impurity concentration in $\mathrm{He}^{+}$ions. The reduction in $\mathrm{Mo}_{2} \mathrm{C}$ with increasing $\mathrm{C}^{+}$impurity concentration in $\mathrm{He}^{+}$ions can be understood in the realm of sufficiently higher amount of $\mathrm{C}$ deposition on top layer. Therefore, major amount of the signals came either from the pure carbon $\mathrm{C}-\mathrm{C}$ layer or from oxidized $\mathrm{C}(\mathrm{C}=\mathrm{O}$, and $\mathrm{O}-\mathrm{C}=\mathrm{O})$ that is preoxidized by open-air exposure.

\subsection{Optical Reflectivity Studies}

For monitoring $\mathrm{C}^{+}$impurity $\mathrm{He}^{+}$ion-induced surface modifications, in particular tailoring of Mo fuzz density, optical reflectivity measurements were also performed and the results were 
summarized in Fig. 5. The figure shows the optical reflectivity spectra in the wavelength range of 200-1100 nm for all the irradiated and pristine mechanically polished to a mirror finish Mo samples (all the five cases; $100 \% \mathrm{He}^{+}, 0.01,0.05$, and $0.5 \% \mathrm{C}^{+}$ions; and $100 \% \mathrm{H}^{+}$ion). Before the reflectivity measurements began, the spectrometer was calibrated with a Spectralon white reference plate having $100 \%$ reflectivity. Thus, in an ideal condition the reflectivity for an ideal mirror will be $100 \%$ and for an ideal black surface [50] will be $0 \%$. The observed reflectivity for the pristine Mo sample was $\sim 42 \%$ (for $\lambda=670 \mathrm{~nm}$ ). The value of reflectivity gradually changes with increasing $\mathrm{C}^{+}$ion impurity $\%$ in $\mathrm{He}^{+}$ions: $\sim 42 \%$ (pristine) to $\sim 0.4 \%\left(100 \% \mathrm{He}^{+}\right.$ion) to $\sim 5.8 \%\left(0.01 \% \mathrm{C}^{+}\right.$ion) to $\sim 11.6 \%\left(0.05 \% \mathrm{C}^{+}\right.$ion $)$to $\sim 19.6\left(0.5 \% \mathrm{C}^{+}\right.$ion $)$to $\sim 30.2\left(100 \% \mathrm{H}^{+}\right.$ ion) (at $\lambda=670 \mathrm{~nm}$ ). The value of reflectivity is directly related to Mo fuzz density and/or thickness, which increase with the roughness of the Mo surfaces. In this way, the changes in the reflectivity values indicate for the changes in Mo fuzz density variations due to ion-irradiation (as compared to pristine, for which we assume zero fuzz density). The sequential enhancement in the reflectivity value indicate the reduction in the Mo fuzz density with increasing $\mathrm{C}^{+}$ion impurity concentration. The findings match well with SEM and AFM studies where gradual reduction (and corresponding enhancement in the C layers on Mo surface) was observed in the Mo fuzz density with increasing $\mathrm{C}^{+}$ion concentration (Fig. 1). The reduction in the reflectivity for $100 \% \mathrm{H}^{+}$ion case as compared to pristine, may be understood in the realm of surface roughening, grain boundaries, and nanostructure formation, due to $100 \mathrm{eV} \mathrm{H}^{+}$ion irradiation.

\section{Conclusions}

Cold-rolled Mo (99.95\% purity) samples of $10 \mathrm{~mm} \times 10 \mathrm{~mm} \times 0.5 \mathrm{~mm}$ were cut from the same Mo sheet, mechanically polished to a mirror-finish, and after then loaded in UHV chamber for ion irradiation experiments. The study involves five cases, viz., pure $\mathrm{He}^{+}$ion, $0.01 \% \mathrm{C}^{+}$ion 
impurity, $0.05 \% \mathrm{C}^{+}$ion impurity, $0.5 \% \% \mathrm{C}^{+}$ion impurity, pure $\% \mathrm{H}^{+}$ion irradiation. For introducing $\mathrm{C}^{+}$ion impurities gas mixtures of $\mathrm{He}$ and $\mathrm{CH}_{4}$ have been chosen in following ratio: 99.95: 0.05, 99.75: 0.25, and 97.5: 2.5. $\mathrm{Pure}^{+}$ion and pure $\% \mathrm{H}^{+}$ion irradiation experiments were performed "for achieving Mo fuzz growth, due to $\mathrm{He}^{+}$ions only", and "for confirming the significance of tiny $0.04-2.0 \% \mathrm{H}^{+}$ions in terms of Mo fuzz evolutions on Mo surface", respectively. Ion energy $(100 \mathrm{eV})$, ion fluence $\left(2.6 \times 10^{24}\right.$ ions $\left.\mathrm{m}^{-2}\right)$, and target temperature (923K) were kept constant for each experiment. Using the above extreme conditions $100 \% \mathrm{He}^{+}$ ion irradiation on Mo surface causes thick Mo fuzz layer showing $0 \%$ optical reflectivity. Enhancement of $\mathrm{C}^{+}$ion impurities in $\mathrm{He}^{+}$ions, causes a sequential enhancement in $\mathrm{C}$ grain coverage (corresponding enhancement in optical reflectivity, and $r m s$ roughness values as well). For $0.5 \% \mathrm{C}^{+}$ion impurity case, a complete depletion of Mo fuzz and thick $\mathrm{C}$ grain coverage have been seen. Ex-situ high-resolution XPS studies on the same sample confirm $\sim 90$ at. \% C (graphite $\mathrm{C}-\mathrm{C}$ and oxidized carbon as major phase) and only $\sim 10 \% \mathrm{Mo}_{2} \mathrm{C}$ phase. Thus, it seems, as if the phenomenon of $\mathrm{He}^{+}$ion irradiation induced Mo fuzz formation can be prevented in the presence of $0.5 \% \mathrm{C}^{+}$ion impurity within the $\mathrm{He}^{+}$ions. The Mo surface shows no significant morphology evolution when irradiated by $100 \% \mathrm{H}^{+}$ions. In this case, the vast majority of the irradiated surface shows no changes after the ion-irradiation while a formation of a few nanostructure appears to form in very small and dispersed areas on the Mo surface. This elucidates that there is no significant role of $\mathrm{H}^{+}$ion impurity in Mo fuzz evolution mechanism. However, more analysis is needed to fully understand the Mo fuzz evolution during $\mathrm{He}^{+}$ion irradiation in the presence of minute $\mathrm{C}^{+}$ion impurities as well as simultaneously during hydrogen isotope irradiation. 


\section{Acknowledgments}

This research was partially supported by National Science Foundation under the PIRE project.

\section{References:}

[1] J.K. Tripathi, T.J. Novakowski, G. Joseph, J. Linke, A. Hassanein, Temperature dependent surface modification of molybdenum due to low energy $\mathrm{He}^{+}$ion irradiation, Journal of Nuclear Materials, 464 (2015) 97-106.

[2] J.K. Tripathi, T.J. Novakowski, A. Hassanein, Tailoring molybdenum nanostructure evolution by low-energy $\mathrm{He}^{+}$ion irradiation, Applied Surface Science, 353 (2015) 1070-1081.

[3] ITER Physics Basis Editors, ITER Physics Expert Group Chairs and Co-Chairs, ITER Joint Central Team and Physics Integration Unit, Chapter 1: Overview and summary Nucl. Fusion, 39 (1999) 2137-2174.

[4] L.M. Evans, L. Margetts, V. Casalegno, L.M. Lever, J. Bushell, T. Lowe, A. Wallwork, P. Young, A. Lindemann, M. Schmidt, P.M. Mummery, Transient thermal finite element analysis of $\mathrm{CFC}-\mathrm{Cu}$ ITER monoblock using X-ray tomography data, Fusion Engineering and Design, 100 (2015) 100-111.

[5] M. Merola, G. Vieider, On the use of flat tile armour in high heat flux components, Journal of Nuclear Materials, 258-263, Part 1 (1998) 672-676.

[6] http://www.iter.org/sci/whatisfusion.

[7] A. Kreter, D. Nishijima, M.J. Baldwin, R.P. Doerner, A. Pospieszczyk, Mitigation of carbon erosion in beryllium seeded deuterium plasma under bombardment by argon and helium ions in PISCES-B, Journal of Nuclear Materials, 417 (2011) 651-654. 
[8] R.A. Pitts, S. Carpentier, F. Escourbiac, T. Hirai, V. Komarov, S. Lisgo, A.S. Kukushkin, A. Loarte, M. Merola, A. Sashala Naik, R. Mitteau, M. Sugihara, B. Bazylev, P.C. Stangeby, A full tungsten divertor for ITER: Physics issues and design status, Journal of Nuclear Materials, 438, Supplement (2013) S48-S56.

[9] G. Janeschitz, Plasma-wall interaction issues in ITER, Journal of Nuclear Materials, 290-293 (2001) 1-11.

[10] G. Federici, P. Andrew, P. Barabaschi, J. Brooks, R. Doerner, A. Geier, A. Herrmann, G. Janeschitz, K. Krieger, A. Kukushkin, A. Loarte, R. Neu, G. Saibene, M. Shimada, G. Strohmayer, M. Sugihara, Key ITER plasma edge and plasma-material interaction issues, Journal of Nuclear Materials, 313-316 (2003) 11-22.

[11] K. Tokunaga, M.J. Baldwin, R.P. Doerner, N. Noda, Y. Kubota, N. Yoshida, T. Sogabe, T. Kato, B. Schedler, Blister formation and deuterium retention on tungsten exposed to low energy and high flux deuterium plasma, Journal of Nuclear Materials, 337-339 (2005) 887-891.

[12] R.P. Doerner, M.J. Baldwin, G.D. Temmerman, J. Hanna, D. Nishijima, J. Roth, K. Schmid, G.R. Tynan, K. Umstadter, Codeposition of deuterium with ITER materials, Nuclear Fusion, 49 (2009) 035002.

[13] D. Nishijima, M.Y. Ye, N. Ohno, S. Takamura, Formation mechanism of bubbles and holes on tungsten surface with low-energy and high-flux helium plasma irradiation in NAGDIS-II, Journal of Nuclear Materials, 329-333, Part B (2004) 1029-1033.

[14] K. Shin, S. Wataru, O. Noriyasu, Y. Naoaki, S. Tsubasa, Formation process of tungsten nanostructure by the exposure to helium plasma under fusion relevant plasma conditions, Nuclear Fusion, 49 (2009) 095005. 
[15] T. Faney, B.D. Wirth, Spatially dependent cluster dynamics modeling of microstructure evolution in low energy helium irradiated tungsten, Modelling and Simulation in Materials Science and Engineering, 22 (2014) 065010.

[16] K. Nordlund, C. Björkas, T. Ahlgren, A. Lasa, A.E. Sand, Multiscale modelling of plasmawall interactions in fusion reactor conditions, Journal of Physics D: Applied Physics, 47 (2014) 224018.

[17] Y.V. Martynenko, M.Y. Nagel, Model of fuzz formation on a tungsten surface, Plasma Physics Reports, 38 (2012) 996-999.

[18] S.I. Krasheninnikov, T. Faney, B.D. Wirth, On helium cluster dynamics in tungsten plasma facing components of fusion devices, Nuclear Fusion, 54 (2014) 073019.

[19] T. Faney, Numerical Simulations of Tungsten under Helium Irradiation, in: Nuclear Engineering, University of California, Berkeley, 2013.

[20] R.P. Doerner, M.J. Baldwin, P.C. Stangeby, An equilibrium model for tungsten fuzz in an eroding plasma environment, Nuclear Fusion, 51 (2011) 043001.

[21] A.L. Esquisabel, Atomistic Simulations of Divertor-Plasma Interactions in Fusion Reactors, in: Department of Physics, University of Helsinki, Helsinki, Finland 2014.

[22] A.V. Barashev, H. Xu, R.E. Stoller, The behavior of small helium clusters near free surfaces in tungsten, Journal of Nuclear Materials, 454 (2014) 421-426.

[23] F. Sefta, Surface Response of Tungsten to Helium and Hydrogen Plasma Flux as a Function of Temperature and Incident Kinetic Energy, in: Nuclear Engineering, University of California, Berkeley 2013.

[24] V.S. Voitsenya, A.F. Bardamid, V.N. Bondarenko, W. Jacob, V.G. Konovalov, S. Masuzaki, O. Motojima, D.V. Orlinskij, V.L. Poperenko, I.V. Ryzhkov, A. Sagara, A.F. Shtan, 
S.I. Solodovchenko, M.V. Vinnichenko, Some problems arising due to plasma-surface interaction for operation of the in-vessel mirrors in a fusion reactor, Journal of Nuclear Materials, 290-293 (2001) 336-340.

[25] G. Federici, C.H. Skinner, J.N. Brooks, J.P. Coad, C. Grisolia, A.A. Haasz, A. Hassanein, V. Philipps, C.S. Pitcher, J. Roth, W.R. Wampler, D.G. Whyte, Plasma-material interactions in current tokamaks and their implications for next step fusion reactors, Nuclear Fusion, 41 (2001) 1967-2137.

[26] Y. Ueda, K. Miyata, Y. Ohtsuka, H.T. Lee, M. Fukumoto, S. Brezinsek, J.W. Coenen, A. Kreter, A. Litnovsky, V. Philipps, B. Schweer, G. Sergienko, T. Hirai, A. Taguchi, Y. Torikai, K. Sugiyama, T. Tanabe, S. Kajita, N. Ohno, Exposure of tungsten nano-structure to TEXTOR edge plasma, Journal of Nuclear Materials, 415 (2011) S92-S95.

[27] G. Sinclair, J.K. Tripathi, P.K. Diwakar, A. Hassanein, Structural response of transient heat loading on molybdenum surface exposed to low-energy helium ion irradiation, Nucl. Fusion, (in press) (2016).

[28] M.J. Baldwin, R.P. Doerner, D. Nishijima, K. Tokunaga, Y. Ueda, The effects of high fluence mixed-species (deuterium, helium, beryllium) plasma interactions with tungsten, Journal of Nuclear Materials, 390-391 (2009) 886-890.

[29] T. Shimada, T. Funabiki, R. Kawakami, Y. Ueda, M. Nishikawa, Carbon behavior on tungsten surface after carbon and hydrogen mixed beam irradiation, Journal of Nuclear Materials, 329-333, Part A (2004) 747-751.

[30] A. Al-Ajlony, J.K. Tripathi, A. Hassanein, Role of carbon impurities on the surface morphology evolution of tungsten under high dose helium ion irradiation, Journal of Nuclear Materials, 466 (2015) 569-575. 
[31] R.P. Doerner, The implications of mixed-material plasma-facing surfaces in ITER, Journal of Nuclear Materials, 363-365 (2007) 32-40.

[32] Y. Ueda, M. Fukumoto, J. Yoshida, Y. Ohtsuka, R. Akiyoshi, H. Iwakiri, N. Yoshida, Simultaneous irradiation effects of hydrogen and helium ions on tungsten, Journal of Nuclear Materials, 386-388 (2009) 725-728.

[33] J. Luthin, C. Linsmeier, Carbon films and carbide formation on tungsten, Surface Science, 454-456 (2000) 78-82.

[34] J.K. Tripathi, S.S. Harilal, A. Hassanein, Low energy $\mathrm{Ar}^{+}$ion irradiation induced surface modification in cadmium zinc telluride (CdZnTe), Materials Research Express, 1 (2014) 035904. [35] www.casaxps.com/berlin/.

[36] S. Takamura, Temperature Range for Fiber-Form Nanostructure Growth on Molybdenum Surfaces due to Helium Plasma Irradiation, Plasma and Fusion Research, 9 (2014) 14051311405131.

[37] D. Nishijima, M.Y. Ye, N. Ohno, S. Takamura, Incident ion energy dependence of bubble formation on tungsten surface with low energy and high flux helium plasma irradiation, Journal of Nuclear Materials, 313-316 (2003) 97-101.

[38] M.J. Baldwin, R.P. Doerner, Helium induced nanoscopic morphology on tungsten under fusion relevant plasma conditions, Nuclear Fusion, 48 (2008) 035001.

[39] S. Ebisu, K. Ohya, T. Tanabe, Dynamic erosion and deposition on carbon and tungsten due to simultaneous bombardment with deuterium and beryllium ions in plasmas, Fusion Engineering and Design, 81 (2006) 253-258. 
[40] L. Pranevicius, L.L. Pranevicius, D. Milcius, C. Templier, B. Bobrovaite, Behavior of carbon readsorbed on tungsten during low energy Ar ion irradiation at elevated temperatures, Fusion Engineering and Design, 83 (2008) 90-95.

[41] J.A. Floro, E. Chason, R.C. Cammarata, D.J. Srolovitz, Physical Origins of Intrinsic Stresses in Volmer-Weber Thin Films, MRS Bulletin, 27 (2002) 19-25.

[42] K. Tanaka, S. Iijima, Carbon Nanotubes and Graphene, Elsevier amsterdam netherlands, 2014.

[43] S.-H. Su, W.-T. Hsu, C.-L. Hsu, C.-H. Chen, M.-H. Chiu, Y.-C. Lin, W.-H. Chang, K. Suenaga, J.-H. He, L.-J. Li, Controllable Synthesis of Band Gap-Tunable and Monolayer Transition Metal Dichalcogenide Alloys, Frontiers in Energy Research, 2 (2014).

[44] Y. Shi, J.-K. Huang, L. Jin, Y.-T. Hsu, S.F. Yu, L.-J. Li, H.Y. Yang, Selective Decoration of Au Nanoparticles on Monolayer $\mathrm{MoS}_{2}$ Single Crystals, Sci. Rep. , 3 (article number 1839) (2013) 1, doi:10.1038/srep01839.

[45] NIST X-ray Photoelectron Spectroscopy Database http://srdata.nist.gov/xps/.

[46] Q. Gao, X. Zhao, Y. Xiao, D. Zhao, M. Cao, A mild route to mesoporous Mo2C-C hybrid nanospheres for high performance lithium-ion batteries, Nanoscale, 6 (2014) 6151-6157.

[47] Z.-Q. Wang, Z.-B. Zhang, M.-H. Zhang, The efficient synthesis of a molybdenum carbide catalystvia H2-thermal treatment of a Mo(vi)-hexamethylenetetramine complex, Dalton Transactions, 40 (2011) 1098-1104.

[48] E.T. Liakakou, E. Heracleous, Transition metal promoted K/Mo2C as efficient catalysts for CO hydrogenation to higher alcohols, Catalysis Science \& Technology, (2016).

[49] L.N. Aleksandrov, V.Y. Shchelkonogov, The diffusion of carbon into tungsten and molybdenum at low carbon concentrations, Powder Metall Met Ceram, 3 (1964) 288-291. 
[50] T. Søndergaard, S.M. Novikov, T. Holmgaard, R.L. Eriksen, J. Beermann, Z. Han, K. Pedersen, S.I. Bozhevolnyi, Plasmonic black gold by adiabatic nanofocusing and absorption of light in ultra-sharp convex grooves, Nat Commun, 3 (2012) 969. 
Table 1: Summary of the binding energy (BE) and full-width half-maximum (FWHM) values for each fitted peak in the high-resolution XPS spectra of Mo-3d.

\begin{tabular}{|c|c|c|c|c|c|c|c|c|c|c|c|c|}
\hline \multirow{2}{*}{ 苂 } & \multicolumn{2}{|c|}{ Mo 3d5/2 } & \multicolumn{2}{|c|}{ Mo 3d3/2 } & \multicolumn{2}{|c|}{$\mathrm{MoO}_{3} 3 \mathrm{~d} 5 / 2$} & \multicolumn{2}{|c|}{$\mathrm{MoO}_{3} 3 \mathrm{~d} 3 / 2$} & \multicolumn{2}{|c|}{$\mathrm{Mo}_{2} \mathrm{C} 3 \mathrm{~d} 5 / 2$} & \multicolumn{2}{|c|}{$\mathrm{Mo}_{2} \mathrm{C} 3 \mathrm{~d} 3 / 2$} \\
\hline & 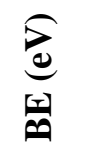 & $\sum_{i=}$ &  & $\sum_{i=1}^{e_{0}}$ & 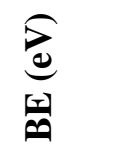 & $\sum_{i=}$ & $\underset{c}{\stackrel{c}{e}}$ & $\sum_{i}$ &  & 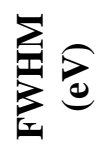 & $\underbrace{8}_{\text {됭 }}$ & 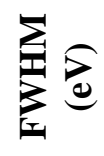 \\
\hline 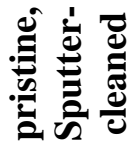 & 228.5 & 1.7 & 231.6 & 2.3 & - & - & - & - & - & - & - & - \\
\hline 范 & 228.6 & 1.7 & 231.1 & 2.5 & 233.3 & 2.5 & 236.5 & 2.1 & - & - & - & - \\
\hline $\begin{array}{c}100 \% \\
\mathrm{He}^{+}\end{array}$ & - & - & - & - & 233.3 & 2.0 & 236.4 & 2.1 & - & - & - & - \\
\hline $\begin{array}{c}\mathbf{0 . 0 5 \%} \\
\mathbf{C}^{+}\end{array}$ & - & - & - & - & 233.2 & 2.0 & 236.3 & 2.1 & 228.6 & 1.7 & 231.7 & 2.3 \\
\hline
\end{tabular}


Table 2: Summary of the binding energy (BE) and full-width half-maximum (FWHM) values for each fitted peak in the high-resolution XPS spectra of C-1s.

\begin{tabular}{|c|c|c|c|c|c|c|c|c|}
\hline \multirow{2}{*}{ Sample } & \multicolumn{2}{|c|}{ Mo $_{2} \mathbf{C}$} & \multicolumn{2}{c|}{ C-C } & \multicolumn{2}{c|}{ C=O } & \multicolumn{2}{c|}{ O-C=O } \\
\cline { 2 - 9 } & BE (eV) & $\begin{array}{c}\text { FWHM } \\
(\mathbf{e V})\end{array}$ & $\begin{array}{c}\text { BE } \\
(\mathbf{e V})\end{array}$ & $\begin{array}{c}\text { FWHM } \\
(\mathbf{e V})\end{array}$ & BE (eV) & $\begin{array}{c}\text { FWHM } \\
(\mathbf{e V})\end{array}$ & BE (eV) & $\begin{array}{c}\text { FWHM } \\
(\mathbf{e V})\end{array}$ \\
\hline $\mathbf{0 . 0 1 \%} \mathbf{C}^{+}$ & 284.6 & 2.1 & 284.9 & 1.5 & 286.2 & 2.1 & 288.2 & 2.5 \\
\hline $\mathbf{0 . 0 5 \%} \mathbf{C}^{+}$ & 284.2 & 2.1 & 284.9 & 1.5 & 286.1 & 2.1 & 288.4 & 2.6 \\
\hline $\mathbf{0 . 5 \%} \mathbf{C}^{+}$ & 283.8 & 1.3 & 284.7 & 1.5 & 285.8 & 2.1 & 288.5 & 2.5 \\
\hline
\end{tabular}


Table 3: Summary of calculated atomic concentrations each peak in the high-resolution XPS spectra

\begin{tabular}{|c|c|c|c|c|c|c|}
\hline \multirow{2}{*}{ sample } & \multicolumn{6}{|c|}{ atomic concentration (\%) } \\
\cline { 2 - 7 } & $\mathbf{M o}$ & $\mathbf{M o O}_{\mathbf{3}}$ & $\mathbf{M o} \mathbf{C}$ & $\mathbf{C}-\mathbf{C}$ & $\mathbf{C}=\mathbf{O}$ & $\mathbf{O - C}=\mathbf{O}$ \\
\hline $\begin{array}{c}\text { pristine @ } \\
\mathbf{1} \mathbf{~ k e V ~ A r} \\
\text { irradiation }\end{array}$ & 100 & - & - & - & - & - \\
\hline pristine & 58.9 & 41.1 & - & - & - & - \\
\hline $\mathbf{1 0 0} \% \mathbf{H e}^{+}$ & - & 100 & - & - & - & - \\
\hline $\mathbf{0 . 0 1} \% \mathbf{C}^{+}$ & - & 45.5 & 24.9 & 10.1 & 14.6 & 4.9 \\
\hline $\mathbf{0 . 0 5} \% \mathbf{C}^{+}$ & - & 34.7 & 20.8 & 15.1 & 21.6 & 7.8 \\
\hline $\mathbf{0 . 5} \% \mathbf{C}^{+}$ & - & - & 9.9 & 48.9 & 35.9 & 5.3 \\
\hline
\end{tabular}



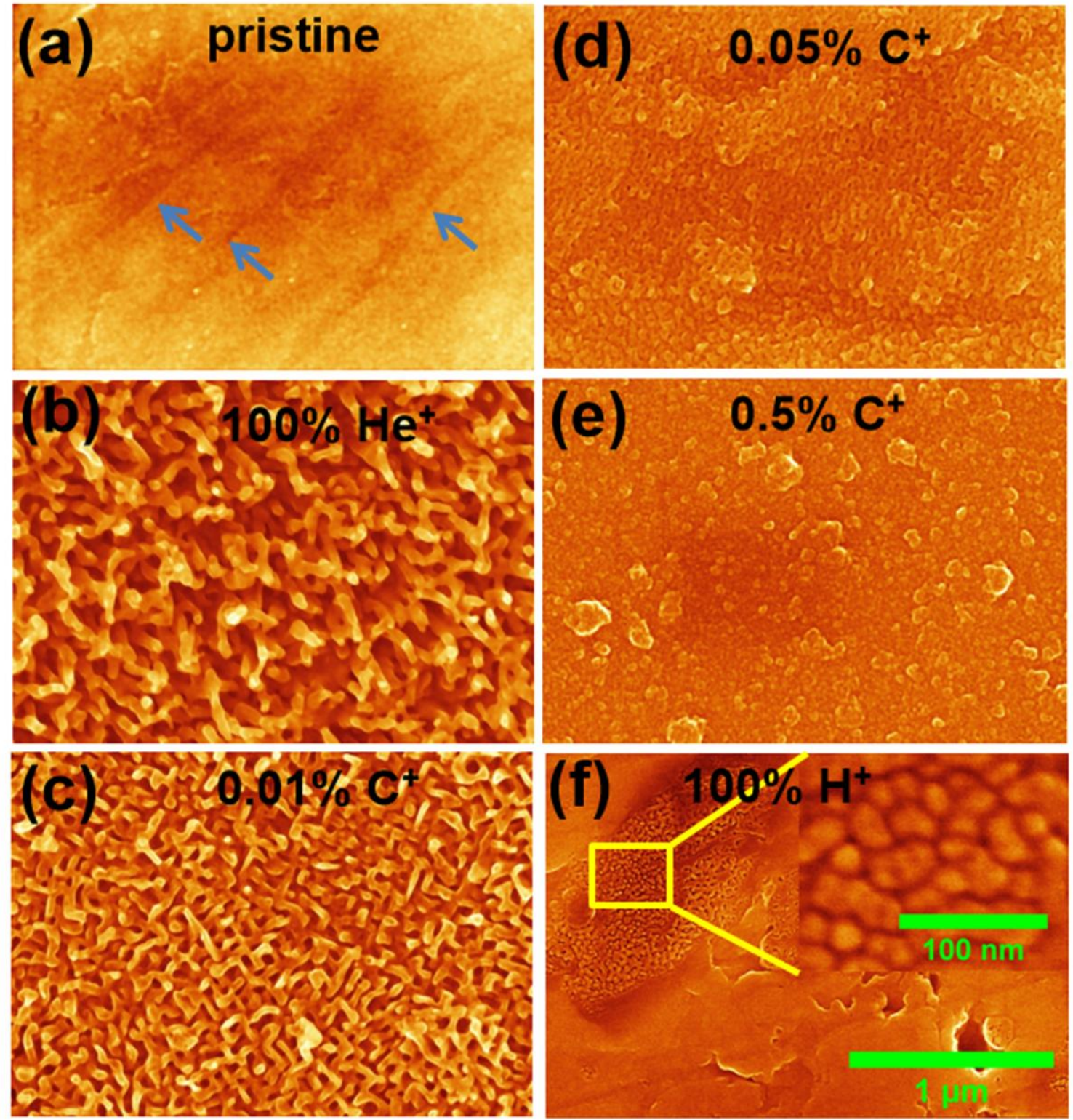

Figure - 1: Field emission (FE) scanning electron microscopy (SEM) imaging of pristine (a) and ion irradiated (b-f) molybdenum surface having a gas mixture of $\mathrm{He}, \mathrm{CH}_{4}$, and $\mathrm{H}_{2}$ in following ratio: $\mathrm{He}: \mathrm{CH}_{4}: \mathrm{H}_{2}::$ 100: 0 : 0 for geting 100\% $\mathrm{He}^{+}$ions (b), 99.95: 0.05: 0 for getting $0.01 \% \mathrm{C}^{+}$ions (c), $99.75: 0.25: 0$ for getting $0.05 \% \mathrm{C}^{+}$ions $(\mathrm{d}), 97.5: 2.5: 0$ for getting $0.5 \%$ $\mathrm{C}^{+}$ions (e), and 0: 0: 100 for geting $100 \% \mathrm{H}^{+}$ions (f). Inset in figure (f) shows a high-resolution SEM image from the marked region in the same figure. Ion energy $(100 \mathrm{eV})$, ion fluence $(2.6 \times$ $10^{24}$ ions $\mathrm{m}^{-2}$ ) and target temperature $(923 \mathrm{~K})$ were kept constant for each experiment. 

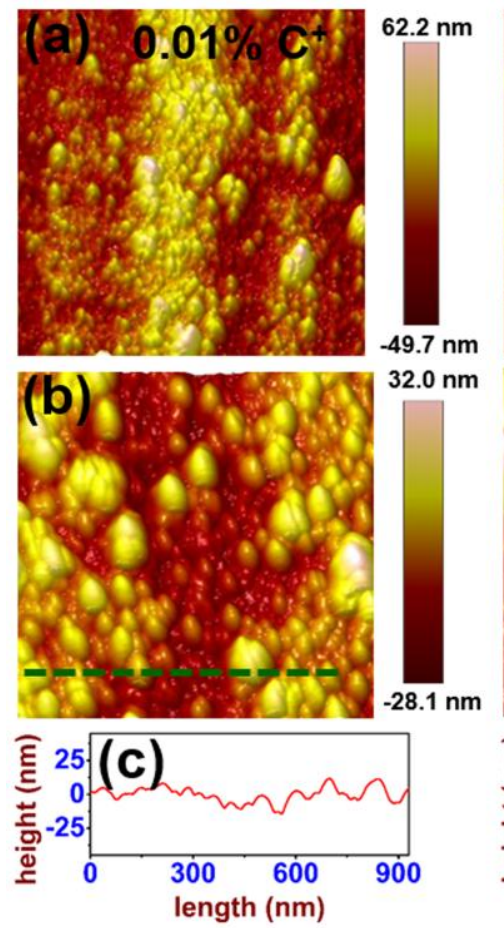
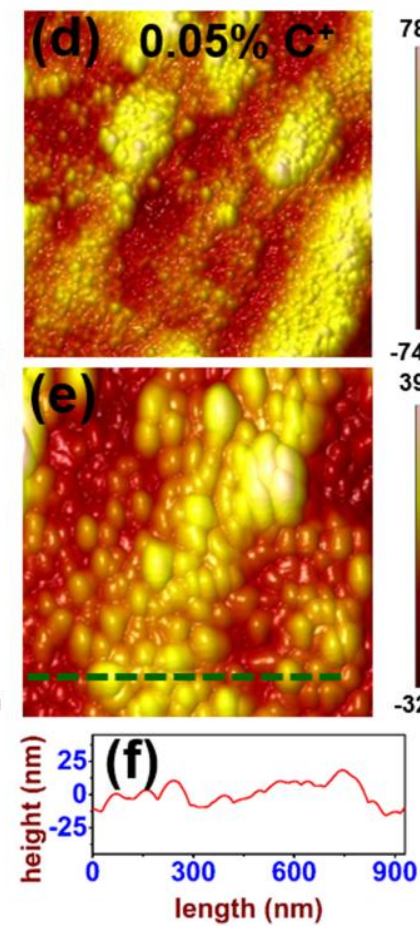



$39.4 \mathrm{~nm}$

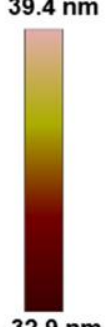

$-32.9 \mathrm{~nm}$

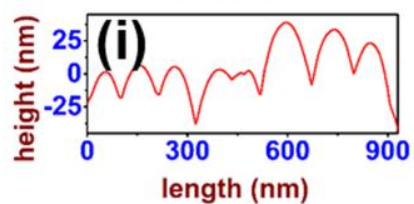

Figure - 2: Atomic Force Microscopy (AFM) topography images (tapping mode) for $\mathrm{C}^{+}$ion impure $\mathrm{He}^{+}$ion irradiated molybdenum surfaces. $0.01 \% \mathrm{C}^{+}$ion case, using a gas mixture of $\mathrm{He}$ and $\mathrm{CH}_{4}$ in the ratio of 99.95: $0.05(\mathrm{a}-\mathrm{c}) ; 0.05 \% \mathrm{C}^{+}$ion case, using a gas mixture of $\mathrm{He}$ and $\mathrm{CH}_{4}$ in the ratio of $99.75: 0.25(\mathrm{~d}-\mathrm{f})$; and $0.5 \% \mathrm{C}^{+}$ion case, using a gas mixture of $\mathrm{He}$ and $\mathrm{CH}_{4}$ in the ratio of $97.5: 2.5$ (g-i). Corresponding line profiles (along the marked green line) in each case have also been shown; indicating a sequential enhancement in the $\mathrm{C}$ grain size (due to nucleation of $\mathrm{C}$ adatoms on Mo surface) and their coverage of the Mo surfaces. 




Figure - 3: Ex-situ XPS core level survey spectra for pristine, $1 \mathrm{keV} \mathrm{Ar}^{+}$ion-sputter-cleaned additional pristine Mo sample (for reference and comparison purpose) and ion irradiated molybdenum surface having a gas mixture of $\mathrm{He}, \mathrm{CH}_{4}$, and $\mathrm{H}_{2}$ in following ratio: $\mathrm{He}: \mathrm{CH}_{4}: \mathrm{H}_{2}$ :: 100: 0: 0 for geting 100\% $\mathrm{He}^{+}$ions , 99.95: $0.05: 0$ for getting $0.01 \% \mathrm{C}^{+}$ions, $99.75: 0.25: 0$ for getting $0.05 \% \mathrm{C}^{+}$ions, $97.5: 2.5: 0$ for getting $0.5 \% \mathrm{C}^{+}$ions, and $0: 0: 100$ for geting $100 \% \mathrm{H}^{+}$ ions (XPS spectra not shown here). Ion energy $(100 \mathrm{eV})$, ion fluence $\left(2.6 \times 10^{24}\right.$ ions $\left.^{-2}\right)$ and target temperature (923K) were kept constant for each experiment. XPS data for the pristine and ion irradiated Mo surfaces are vertically shifted for clarity. 

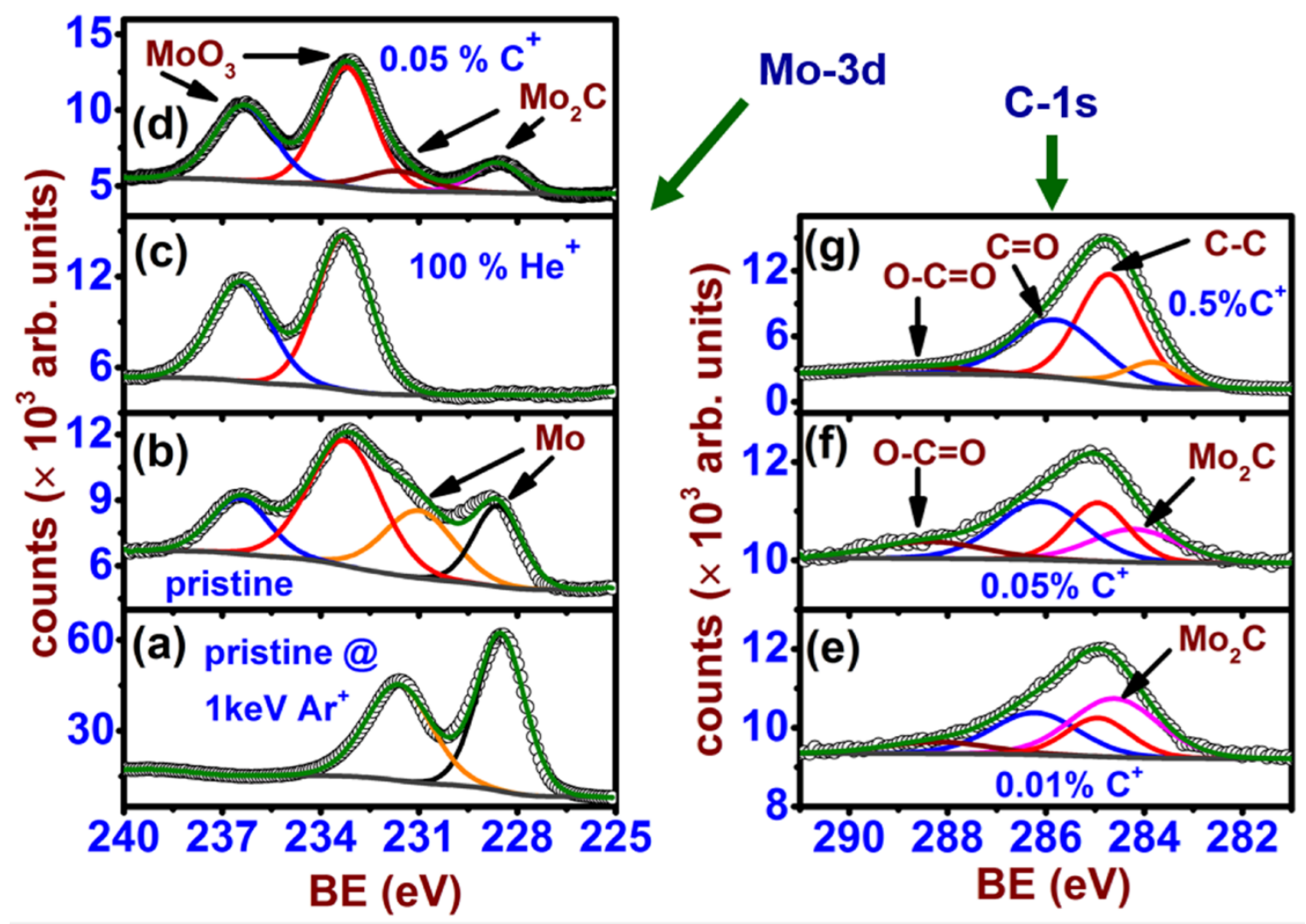

Figure - 4: Ex-situ high-resolution core level XPS spectra Mo-3d doublet (a-d; left column) and $\mathrm{C}-1 \mathrm{~s}$ (e-g, right column). XPS spectra for $1 \mathrm{keV} \mathrm{Ar}^{+}$ion-sputter-cleaned additional pristine Mo have been generated and incorporated here for reference and comparison purpose. Ion irradiation experiments on molybdenum surface have been performed using a gas mixture of $\mathrm{He}, \mathrm{CH}_{4}$, and $\mathrm{H}_{2}$ in following ratio: $\mathrm{He}: \mathrm{CH}_{4}: \mathrm{H}_{2}::$ 100: 0: 0 for geting100\% $\mathrm{He}^{+}$ions , 99.95: 0.05: 0 for getting $0.01 \% \mathrm{C}^{+}$ions, $99.75: 0.25: 0$ for getting $0.05 \% \mathrm{C}^{+}$ions, $97.5: 2.5: 0$ for getting $0.5 \%$ $\mathrm{C}^{+}$ions, and 0:0: 100 for geting100\% $\mathrm{H}^{+}$ions (XPS spectra not shown here). Ion energy (100 $\mathrm{eV})$, ion fluence $\left(2.6 \times 10^{24}\right.$ ions $\left.\mathrm{m}^{-2}\right)$ and target temperature $(923 \mathrm{~K})$ were kept constant for each experiment. 


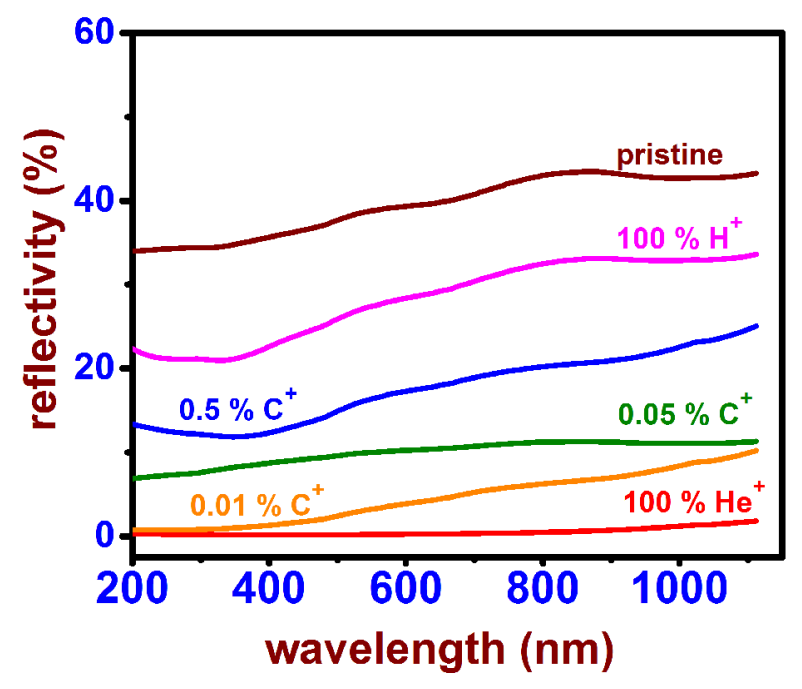

Figure - 5: Optical reflectivity measurements (as function of wavelength) for pristine and ion irradiated molybdenum surface having a gas mixture of $\mathrm{He}, \mathrm{CH}_{4}$, and $\mathrm{H}_{2}$ in following ratio: He: $\mathrm{CH}_{4}: \mathrm{H}_{2}::$ 100: 0: 0 for geting 100\% $\mathrm{He}^{+}$ions , 99.95: 0.05: 0 for getting $0.01 \% \mathrm{C}^{+}$ions, 99.75 : 0.25 : 0 for getting $0.05 \% \mathrm{C}^{+}$ions, $97.5: 2.5$ : 0 for getting $0.5 \% \mathrm{C}^{+}$ions, and $0: 0$ : 100 for geting $100 \% \mathrm{H}^{+}$ions. Ion energy $(100 \mathrm{eV})$, ion fluence $\left(2.6 \times 10^{24}\right.$ ions $\left.\mathrm{m}^{-2}\right)$ and target temperature $(923 \mathrm{~K})$ were kept constant for each experiment. Note the almost zero reflectivity for Mo fuzz formation structures. 




Graphical Abstract 